\title{
Hands Make Us Human
}

Arabena, Kerry ${ }^{1}$

1. Centre for Health Equity, Melbourne School of Population and Global Health, The University of Melbourne, Carlton VIC, 3010 Australia

Running Head: Hands Make Us Human

Key Words: Mandy Nicholson; One Health; Congress 2016

Word Count: 1,365

\section{Corresponding Author: n/a}

\section{Hands Make Us Human}

The hand design for the cover of this edition is the work of Mandy Nicholson, an artist who over the past 18 years has produced carvings, etchings, prints, ceramic pieces, murals, corporate logos, children's clothing and public art works. She is a proud member of the Wurundjeri-willam clan, a people of the Indigenous Australian nation who belong to the Woiwurrung language group in the Kulin Alliance. For thousands of years, the Wurundjeri peoples have occupied traditional lands that include the Birrarung (Yarra River), its tributaries and the present location of Melbourne, site of the $4^{\text {th }}$ International Congress for One Health and $6^{\text {th }}$ Biennial Congress of the International Association for Ecology and Health.

For Aboriginal and Torres Strait Islander peoples, the symbol of the hand has multiple meanings. I clearly remember the hands of my grandmother's sister. They were gnarled and twisted from arthritis in her older age, but beautifully shaped like a wind-swept ancient tree. Her hands reflected both her hard work and her elegance; they defined who she was and how she lived her life. Her morals and values were captured in her hands after a lifetime of providing comfort and nourishment to others.

The meaning of hands is deeply embedded in the culture and consciousness of Aboriginal and Torres Strait Islander peoples and so represented in this design - as an extension of greeting to visitors, and as symbolic of ancient ecological knowledge and custom. Hands also represent 
presence and of humans in place; and of men's and women's capacity to hold and nurture children into adulthood. One cannot see hands in this cultural context without some degree of ecological consciousness. To understand and grasp the artist's meaning of hands, we also need to grapple with what it means to be human. In the words of Fritjof Capra (1982) we need to move 'beyond the shallow concern of environmental protection toward recognition and valuing the balance required to live in the confines of our planetary ecosystem'.

The essence of these multiple meanings is contained in the traditional greeting of the Wurundjeri peoples of the Kulin nations, with two statements in particular having special significance for this edition. The first, when translated, means 'extending the hand of friendship'. The Wurundjeri people pride themselves on a tradition of hospitality and generosity to travellers from other nations. Extending the hand of friendship is embedded in an ancient cultural protocol that affirms both the traditional custodians of the land and permits visitors to enter their territory. This element of welcome not only provides Aboriginal people with a place in modern Australian society; it formalizes in a respectful way that we meet on the lands of Aboriginal peoples whose lives and cultures have been disrupted through the ongoing process of colonization and modernization.

This open hand design, with fingers fully extended in greeting, crisscrossed with rivers and tributaries, depicts the lands which nourished the artist's ancestors for thousands of years and symbolizes the deep desire of the Wurundjeri custodians that all visitors to Melbourne are safe, and do not come to harm while on their traditional lands. Delegates to the One HealthEcoHealth Congress are travelling from more than 80 different countries, with many coming to Australia for the first time. They are following a traditional custom of acknowledgment that is more than 40,000 years old and participating in a ritual of information exchange across and between people from different places near the mouth of the river. These celebratory events often commence with a handshake; an exchange of gifts that speaks to a genuine, equitable partnership in which opportunities to learn and contribute are the same for all engaged.

Often ecological knowledge and custom formed the basis of these exchanges. Aboriginal people were seasonal travellers - knowing the availability of resources, how to get them, how long they would last. Thus, this hand design also symbolizes the collective power of a people in the region 
through sharing resources and of reciprocity. The importance of both ecological knowledge and the custom of exchange are evident in the second statement of the traditional Wurundjeri welcome: 'When you care for country, country cares for you' (quoted from Wurnudjeri Elder Joy Murphy Wandin). These sentiments are also captured in the design of the front cover that is painted in blues and greens to represent nature and all who are held within it. Understanding the land through seasonal observations was once essential to survival and is, today, essential to its management.

Traditional welcomes that encapsulate the principle of care for Country so that it might care for you are also a lesson for protecting and conserving habitat and preserving plants and animals and an instruction for how to live in the confines of Country. Because the future of our peoples is so closely aligned with that of the environments to which we belong and move through, care for Country also embodies a belief that our understanding of self can expand to include that of nature. Aboriginal people through their extension of a hand in friendship and care for Country also asks people to widen and deepen their understanding of 'self' to include nature. Care of our personhood necessarily involves the care and protection of nature, which is why every place, plant and animal has been given an Aboriginal name and, if required, a clan connection.

This hand design also symbolizes human presence on the continent of Australia. The presence of Aboriginal and Torres Strait islander people on this continent has been highly contested in recent times, but ancient hand stencils show that parts of Australia have been occupied for more than 30,000 years. Some stencils were left to mark a nation's territory or a hierarchy of importance and are still used today with modern hand stencils found on city walls and in company logos. The organization Australians for Native Title and Reconciliation (ANTaR) also uses a hand to promote reconciliation between indigenous and non-Indigenous Australians. The Sea of Hands used by ANTaR represents a people's movement to reconcile and overcome conflict regarding the long-term presence of Aboriginal people in Australia and symbolic need to have a genuine and equal partnership between First peoples and all other Australians.

Aboriginal and Torres Strait Islander people have a belief that our children are held in the wombs of their mothers, and born into the womb of their fathers - their lands. This embodiment of Country as a source of continued sustenance places people as an extension of 